\title{
A Study on the Health Status of Elderly Irular Tribal Women in Kancheepuram District
}

\author{
Mary Angeline Santhosam, ${ }^{1}$ Umesh Samuel ${ }^{2}$ \\ ${ }^{1}$ (Mrs .Mary Angeline Santhosam, Head Department of Social work (SF), Madras School of Social Work, India.) \\ ${ }^{2}$ Dr. Umesh Samuel, Associate Professor, Department of Social Work, Bishop Heber College, India)
}

\begin{abstract}
Indian tribals are a heterogeneous group; most of them remain at the lowest stratum of the society due to various factors like geographical and cultural isolation, low levels of literacy, primitive occupations, and extreme levels of poverty. The present paper attempts to study the health problems of the elderly Irular women in three villages of Kancheepuram district. A total of 30 elderly tribal were interviewed using a pre-tested Interview schedule. Around 66\% of the women belonged to the age group of 60-69 years old. A majority of them had health problems such as hypertension followed by arthritis, diabetes, constipation etc. The results of the study showed that there is a need for geriatric clinics that can take care of their physical and psychological needs. It further stressed accessibility of health services as a main reason for the elderly not availing the health care services. The study also suggested provision of mobile clinic to cater to the needs of the community every month on a selected date on a regular basis.
\end{abstract}

Keywords: Health status, Tribal women

\section{INTRODUCTION}

Ageing is mainly associated with social isolation, poverty, apparent reduction in family support, inadequate housing, impairment of cognitive functioning, mental illness, widowhood, loss, bereavement, limited options for living arrangement and dependency towards end of life. Generally, at household level, cultural norms and practices and socio-economic factors determine the extent of health problems among women. Change in socio-economic status and various health problems adversely affect an individual's way of life during old age. In India the size of the elderly population, i.e. persons above the age of 60 years is fast growing although it constituted only $7.4 \%$ of total population at the turn of the new millennium. For a developing country like India, this may pose mounting pressures on various socio economic fronts including pension outlays, health care expenditures, fiscal discipline, savings levels etc. Again this segment of population faces multiple medical and psychological problems. India is home to almost half the tribal population of the world.

Tribals are characterized by a distinctive culture, primitive traits, and socio-economic backwardness. The tribal's of India, constituting $8.2 \%$ of the total population ( 84 million), belong to around 698 communities or clans. Around 75 of these groups are called primitive tribal groups due to pre-agricultural level of knowledge, extreme backwardness, and a dwindling population. However, the exact number of tribal groups may be lesser than 500 due to group-overlapping in more than one state.

Although scheduled tribes are accorded special status under the fifth/sixth schedules of the Indian Constitution, their status on the whole, especially their health still remains unsatisfactory. Tribal communities in general and primitive tribal groups in particular are highly disease prone. Also they do not have required access to basic health facilities. They are most exploited, neglected, and highly vulnerable to diseases with high degree of malnutrition, morbidity and mortality (Balgir, 2004[1]). Their misery is compounded by poverty, illiteracy, ignorance of causes of diseases, hostile environment, poor sanitation, lack of safe drinking water and blind beliefs, etc.

Some of the preventable diseases such as tuberculosis, malaria, gastroenteritis, filariasis, measles, tetanus, whooping cough, skin diseases (scabies), etc. are also high among the tribals. Some of the diseases of genetic origin reported to be occurring in the Indian tribal population are sickle cell anemia, alpha- and betathalassemia, glucose-6-phosphate dehydrogenase (G6PD) deficiency, etc. (Balgir, 2004[2]). Night blindness, sexually transmitted diseases are well known public health problems of tribals in India.

This paper explores the Health problems of the elderly in the Irular Tribal women. It also explores the accessibility and availability of public health services to these disadvantaged women in the tribal population at Kancheepuram district of Tamilnadu and suggests solutions. 
The objectives of the study were to:

\section{OBJECTIVES}

1. To study the socio-demographic characteristics of the elderly Irular women

2. To identify the health problems of the elderly Irular women.

3. To find out the problems faced in accessibility of health services by these women

4. To highlight the role of the social worker in creating awareness of the various health services available from the government for these women.

5. To highlight the role of social worker in creating awareness on the causes, prevention and treatment of these problems.

\subsection{Selection of study area}

\section{METHODOLOGY}

The present study was carried out in three villages among the tribal hamlets of Melkalvoy, Pinnal nagar, and Kalvoy, in Kancheepuram district. All the three hamlets have similar socio-demographic backgrounds. These hamlets tribal communities belong to the Irular community.

\subsection{Sample design}

The sample consisted of 30 females belonging to the age groups between 60-80. All the elderly in the three villages were taken as the sample and hence no sampling method was used.

\subsection{Tools of data collection}

The main tool used for data collection was a semi-structured interview schedule. It was constructed after reviewing the past researches on elderly conducted in India with the tribal's covering the various health aspects.

\section{RESULTS AND DISCUSSION}

\subsection{Socio-demographic Characteristics of the Elderly}

The sample consisted of elderly tribal women $(n=30)$. Out of this total number $60 \%$ were between the age group of 60- 69 years, 30\% between 70-79 years, and the remaining $10 \%$ below 80\%. This was purposefully done to study the change in the nature of health problems with increase in age. A majority of the respondents were Hindus (96.33\%), and the remaining Christians 3.67\%. 86.66\% of the respondents were married and the remaining females were widows. 93.33 percent respondents who were illiterate the rest were literate and had attended Primary school. Majority of these women lived in joint families and $83.33 \%$ lived in hut houses near their children (Who lived in pucca houses). The remaining $16.66 \%$ lived in tiled houses with their children.

\subsubsection{Economic Status}

Although economic status is a very relative term but for the purpose of the present study income of the elderly was taken as the parameter to determine the health status of the respondents. As per the data except onefourth of the respondents, the rest of them belonged to lower/medium economic group. The elderly women most of them were housewives and had no income. They depended on their children for food and shelter and all the other needs. The economic status of the widows (30\%) was very pathetic. They had to do all house hold work for a square meal.

\subsubsection{Occupational Status}

Nearly $46.66 \%$ of the elderly women were housewives taking care of the grandchildren and attending to household chores. The women who were agriculture coolie (10\%) and construction workers (10\%) also were employed on daily wages and employed only for 30-50 days per year. Other days they remain idle at home attending to household chores.

\subsection{Health Aspects}

All the respondents had health problems, the most common being hypertension (22\%), arthritis (17\%), diabetes $(10 \%)$, or constipation (2\%.) Others included anemia $(10 \%)$, skin problems $(12 \%)$ vision problems $(18 \%)$ and other minor ailments (5\%). The presence of bitot's spots on almost $4 \%$ of the women studied shows signs of Vitamin A deficiency. It is seen that most of the respondents had more than one health problem. Hypertension, arthritis and diabetes were found to be more common among females. Most (60\%) of the elderly women interviewed had been affected by any one or a combination of this diseases and symptoms like Parasitic infestation, Viral and Fungal infections, Conjunctivitis, Cough and Cold, Diarrhoea and Dysentery more than 10 times in their life till date. (Balgir 2005[3]) in his study on several communicable diseases prevalent among the 
tribals of Orissa found out that Tuberculosis, Hepatitis, Sexually Transmitted Diseases (STDs), Malaria, Filariasis, Diarrhoea and Dysentry, Jaundice, Parasitic infestation, Viral and Fungal infections, Conjunctivitis, Yaws, Scabies, Measles, Leprosy, Cough and Cold, HIV/AIDS, which is spreading like wild fire, etc. due to lack of sanitation and unhygienic living.

\subsection{Problems faced by the elderly in accessibility of health services}

With increasing age, the health problems increase but the economic resources of the elderly usually show a decline. Almost 50\% of the tribal elderly reported that the doctors were not present in the PHC (nearest $20 \mathrm{kms}$ away) most of the time. Previous studies show that almost $20 \%$ of the PHCs in tribal areas are not staffed with doctors (15\% in non-tribal areas) and $15 \%$ of the posts for paramedical workers are vacant (Soudarssanane et al 2012[4]).

They often use home remedy or indigenous medicines for their ailments as the first preference. For them, seeking medical services is expensive unless it is from a public hospital. The elderly tribal generally is the last person in a household to seek or to demand the medical aid. Their inability to pay for their treatment is a problem. Another major problem is that they have the habit of getting treatment always free and the major reason quoted was poverty and family not willing to pay for their health problems. Most of the respondents could not gain access to medical care services due to under-developed communication and lack of transport facilities.

\subsection{Role of social worker}

In India, due to the elite structure of health care facilities, the poor and the elderly women are often neglected. In the study undertaken it was found that once the elderly fall sick, they do not visit the PHC or clinics or any outpatient departments.

Social work is mainly believed to be problem oriented but while working with the elderly it may be process oriented. The most appropriate place through which they can operate is while they are employed as social workers in public/government hospital or while they are employed in community based rehabilitation schemes in the communities.

The specific intervention strategies that can be undertaken by the social worker are:

\subsubsection{Creating awareness}

- To create an awareness for regular medical checkups to ensure prevention, and early detection of the disease.

- Awareness about nutrition and health related issues of the tribal elderly are to be formulated.

- Awareness and preventive programme about common prevalent diseases in Self Help groups, schools and in the community on a regular basis.

- $\quad$ Spreading awareness through information dissemination by preparing booklets (more of pictures and small texts), videocassettes etc. on health and nutrition related issues.

- Conducting street play, Puppetry and Mime etc with the help of social work trainees to create awareness on health and nutrition.

\subsubsection{Training}

- $\quad$ Training of local women leaders in disease prevention, and referral services

- For nutritional deficiencies, the tribal women to be trained in healthy food habits based on the available foods through Nutritional education programmes.

\subsubsection{Health services by government}

- $\quad$ Arrange for Health checkups and other related services at the doorsteps for those who are immobile.

- Networking with local NGOs to come forward and volunteer to work in the area of health for the elderly.

- There should be separate geriatric clinics in the private/government hospitals.

- It is necessary to set up subsidized health care for the elderly with special units in hospitals with free or highly subsidized medicines.

- $\quad$ Encourage the community women to have Kitchen garden for each house

- $\quad$ Preventive approach like immunization, anti-infection measures, and various other prophylactic aspects should be given more importance.

\section{SUGGESTIONS}

- A mobile van to cater to the needs of the community every month on a selected date on a regular basis. 
- Providing social and economic incentives and support for combating the common prevalent communicable and non-communicable diseases in the tribal community through NGOs run by tribals.

\section{CONCLUSION}

Health care is one of the most important of all human endeavors to improve the quality of life especially of the tribal people (Balgir, 1997[5]; 2000[6]). Health must meet the need of the people, as they perceive them. Health cannot be imposed from outside against people's will. It cannot be dispensed to the tribal people. (Balgir, 2000[7]). It implies the provision of conditions for normal, physical and mental development and functioning of human being individually as well as in a group. All these problems have an impact on the quality of life in old age and health care at the time of need. In traditional Indian societies, joint family system used to take care of most of these social issues. In this study most of the elderly women live in joint families but they do not get the care and concern those traditional Indian joint families gave. They are thought of as dependents and merely helpers for their children. These elderly tribal women prefer to use indigenous medicines for their illness and feel that it is a waste of time to travel to places away at a long distance form home for treatment. If health services are available at their door step it would be a welcome change for them.

The results of the study showed that there is a need for geriatric counseling centers that can take care of their physical and psychological needs. Any tribe must be encouraged to organize itself in order to take advantages of the programs designed for the development and health in the light of human genetics, prophylactic immunization, socio-cultural traditions and eco-friendly environment. Further health care system at various levels in our country is designed for the general population and no special provisions/preferences are provided in the system to take care of the elderly especially the tribals.

The major limitation of this study was that age specific diseases could not be ascertained as the tribal women were not able to tell their exact age. Also they were not allowed to interact with outside people for fear of their status being revealed to others. Getting a sample of elderly women from other villages was difficult and some of them simply refused to answer questions related to disease. Future comparative study on the health seeking behavior of the Irular tribal women in plains and the tribal women in the hilly terrain is worth exploring and is the next goal of the researcher. There is an emerging need to pay greater attention to ageing-related issues and to promote holistic policies and programmes in dealing with the ageing society especially the Irular tribes.

\section{ACKNOWLEDGEMENT}

The authors would like to thank Dr.R.Christodos Gandhi, I.A.S. Additional Chief Secretary/Development Commissioner, Planning Development and Special Initiatives Department government of Tamilnadu for his motivation,guidance and opportunity. My special thanks to Mrs. Sournalatha, Managing Trustee and Mr. Balaji, Financial Trustee, ASSET for their help in data collection. This article is dedicated to the elderly Irular tribal women for their cooperation during the study.

\section{REFERENCES}

[1] Balgir RS. 2004a. Dimensions of rural tribal health, nutritional status of Kondh tribe and tribal welfare in Orissa: a biotechnological approach. Proceedings of the UGC Sponsored National Conference on Human Health and Nutrition: A Biotechnological Approach (Lead Lecture), 12-13th December 2004. Thane. pp. 47-57.

[2] Balgir RS. 2004b. Health care strategies, genetic load, and prevention of hemoglobinopathies in tribal communities in India. South Asian Anthropologist. Vol. 4: pp 189-198.

[3] Balgir RS. 2005a. Biomedical anthropology in contemporary tribal society of India. In: Behera, Deepak Kumar \& Pfeffer, Georg (Eds). Contemporary Society: Tribal Studies (Tribal Situation in India). New Delhi: Concept Publishing Company. Vol. (6). pp 292- 301 .

[4] Soudarssanane M Bala,Thiruselvakumar.D, Overcoming the problems in the practice of Public helath among tribals in India, Indian Journal of Community Medicine, Volume 34, Issue 4, October 2009.

[5] Balgir RS. 1997. Khonds - health status. In: Madhava Menon T, Sivathanu C, Prasanth KP, Sasikumar M, Mathur PRG (Eds.). Encyclopedia of Dravidian Tribes. Trivendrum: The International School of Dravidian Linguistics. pp. 21-29.

[6] Balgir RS. 2000a. Human genetics, health and tribal development in Orissa. In: P Dash Sharma (Ed.). Environment, Health and Development: An Anthropological Perspective. Ranchi: S.C.Roy Institute of Anthropological Studies. pp. 87-104.

[7] Mohammad Awais Tosib Alam Mohd. Asif, Socio-economic empowerment of tribal women: An Indian perspective, International Journal of Rural Studies (IJRS), vol. 16 no. 1 October 2009, ISSN 1023-2001 www.ivcs.org.uk/IJRS Article 5 Page 4 of 11.

[8] K. Mallikharjuna Rao, N. Balakrishna, N. Arlappa, A. Laxmaiah and G.N.V. Brahmam, Diet and Nutritional Status of Women in India, National Institute of Nutrition, (Indian Council of Medical Research), Jamai-Osmania,P.O., Hyderabad 500 007, Andhra Pradesh, India.

[9] R.S. Balgir, Tribal Health Problems, Disease Burden and Ameliorative Challenges in Tribal Communities with Special Emphasis on Tribes, Proceeding of National Symposium on Tribal Health. 